\title{
Three versions of the Short Alcohol Dependence Data Questionnaire (SADD) in Mexican popu- lation: a comparative analysis of psychometric properties and diagnostic accuracy
}

\author{
Alejandro Pérez-López, ${ }^{1}$ Luis Villalobos-Gallegos, ${ }^{1}$ María del Carmen Viveros Domínguez, ${ }^{2}$ \\ Javier Grave-Moreno,' Rodrigo Marín-Navarrete'
}

Original article

\section{ABSTRACT}

\section{Background}

The Short Alcohol Dependence Data Questionnaire (SADD) has shown good reliability and validity in previous studies. In Mexico, although it is widely used in addiction treatment centers, little is known about its psychometric properties and diagnostic accuracy.

\section{Objective}

Hence, this study performed a Confirmatory Factorial Analysis (CFA) on three $\operatorname{SADD}$ versions $(15,14$ and 12 items) and examined their operating characteristics.

\section{Method}

The sample included 570 individuals from the 30 Addiction Residential Centers localized in the central zone of Mexico.

\section{Results}

The three versions showed an internal consistency of $>.90$, fair goodness-of-fit, and significant correlations with the Mini International Neuropsychiatric Interview (MINI) 5.0 Alcohol dependence (AD) diagnostic criteria. The analysis of the operating characteristics revealed that each version accounted for $84-85 \%$ of the area under the curve (AUC).

\section{Discussion and conclusion}

The three SADD versions possess reliability and validity properties for the assessment of the alcohol dependence syndrome (ADS) and adequate diagnostic accuracy for the improvement of patients with $A D$ in residential settings.

Key words: Alcohol dependence, SADD, psychometric properties, construct validity, diagnostic accuracy.

\section{RESUMEN}

\section{Antecedentes}

La Breve Escala de Dependencia al Alcohol (BEDA) ha mostrado confiabilidad y validez en estudios previos. En México, a pesar de que se ha utilizado ampliamente en programas de tratamiento para las adicciones, se conoce muy poco sobre sus propiedades psicométricas y su eficiencia diagnóstica.

\section{Objetivo}

Por lo tanto, el presente estudio realizó un Análisis Factorial Confirmatorio (AFC) en tres diferentes versiones de la $\operatorname{BEDA}(15,14$ y 12 reactivos) y examinó sus características operativas.

\section{Método}

La muestra incluyó 570 personas que recibían atención en centros de tratamiento residencial para las adicciones de la zona central de México.

\section{Resultados}

Las tres versiones mostraron una consistencia interna $>.90$, adecuada bondad de ajuste y correlaciones significativas con la Mini Entrevista Neuropsiquiátrica Internacional, v. 5.0, de criterio diagnóstico de Dependencia al Alcohol (DA). El análisis de las características operativas reveló que cada versión representó $84-85 \%$ del área bajo la curva.

\section{Discusión y conclusión}

Las tres versiones de la BEDA poseen propiedades de confiabilidad y validez para la evaluación del síndrome de dependencia al alcohol (SDA) y adecuada eficiencia diagnóstica para el mejoramiento de los pacientes con dependencia al alcohol en escenarios residenciales.

Palabras clave: Dependencia al alcohol, BEDA, propiedades psicométricas, validez de constructo, eficiencia diagnóstica.

Instituto Nacional de Psiquiatría Ramón de la Fuente Muñiz. Clinical Trials Unit on Addiction and Mental Health.

2 Consejo Estatal Contra las Adicciones del Estado de Hidalgo.

Correspondence: Rodrigo Marín-Navarrete, Instituto Nacional de Psiquiatría Ramón de la Fuente Muñiz, Clinical Trials Unit on Addiction and Mental Health, Calz. México-Xochimilco 101, San Lorenzo Huipulco, Tlalpan, 14370, México, D.F., México. Phone: (+52) (55) 4160 - 5481. E-mail address: rmarin@nprf.gob.mx

Received first version: October 14, 2014. Accepted: June 25, 2015. 


\section{BACKGROUND}

According to the literature, alcohol use disorders (AUD) are among the most important risk factors for traumatic injuries, family problems, crime, violence, and economic loss. ${ }^{1,2}$ They account for $4.2 \%$ of the global disability-adjusted life years (DALY) in low- and middle-income countries, as well as $6.7 \%$ of global the DALY in high-income countries. ${ }^{3}$ In Mexico, it is estimated that alcohol use is among the four leading risk factors responsible for $64.5 \%$ of the DALY in general population, which impact overall on the health care system. ${ }^{4}$ Therefore, it is relevant to identify individuals with AUD in order to reduce the disease burden attributable to alcohol.

Many strategies have been employed to assess AUD, including structured clinical interviews, such as the Composite International Diagnostic Interview, ${ }^{5}$ and semi-structured clinical interviews, such as the Mini International Neuropsychiatric Interview. ${ }^{6}$ Self-report questionnaires might be also useful tools to screen patients with AUD, taking less time and not requiring special training for their administration. ${ }^{7,8}$

Among these, we found the Severity of Alcohol Dependence Questionnaire (SADQ), the Alcohol Dependence Scale (ADS) and the Short Alcohol Dependence Data Questionnaire (SADD), all based on the construct of the alcohol dependence syndrome (ADS) described by Edwards and Gross. ${ }^{9}$ The SADQ is a 20-item questionnaire which emphasizes withdrawal symptoms and physical dependence. ${ }^{10}$ However, it is argued that the biological emphasis of the SADQ is less likely to have discriminative power in mild and moderate dependence. ${ }^{11}$ Its counterpart, the ADS, is a 25-item questionnaire that evaluates psychophysical withdrawal symptoms and loss of behavioral control. ${ }^{12}$ However, its lack of accuracy with the Diagnostic and Statistical Manual of Mental Disorders Fourth Edition (DSM-IV) alcohol dependence (AD) was recently revealed. ${ }^{13}$ On the other hand, the SADD, derived from the Alcohol Dependence Data (ADD) questionnaire, exhibits high correlation $(r=.92)$ with ADD scores. ${ }^{14}$ The SADD is particularly sensitive in evaluating mild- to moderate-range dependence, because it includes cognitive, behavioral and biological components. ${ }^{14}$ The original SADD version reported item-total correlations $>.50$, as well as a split-half reliability of $r=.87$. Davidson and Raistrick ${ }^{11}$ reported several studies that measured the concurrent validity of the SADD with associations from moderate to high (.49-.83). Davidson et al. ${ }^{15}$ suggested using the SADD as a 14-item questionnaire as item 9 showed low correlation with the total score.

Among the studies that evaluated the SADD in countries outside the U.K., we found studies in Brazilian and Indian populations. The first good test-retest reliability was found in a self-report of .90 and a interviewer form of $.81 .^{16}$ In the latter, the SADD was modified and validated with a 12-item version. Exploratory Factorial Analysis results in a unifactorial model that explained $59.3 \%$ of the variance. The authors referred that all the items demonstrated a factor loading of $>.5$, which is evidence of internal validity, as well as significant association among SADD scores with the amount of alcohol consumed $(\mathrm{r}=.62)$ and social dysfunction $(\mathrm{r}=.56)$ as external validity. ${ }^{17}$

In Mexico, the SADD was translated by Echeverría, Oviedo and Ayala, ${ }^{18}$ but its psychometric properties were later reported by Sánchez ${ }^{19}$ in an unpublished work using an outpatient sample. This obtained a good internal consistency $(\alpha=.84)$ and, in an EFA, a factorial model that explains $56.41 \%$ of the variance. The SADD is widely used as a screening instrument in a brief intervention for at-risk drinking at outpatient addiction treatment centers. ${ }^{20} \mathrm{How}$ ever, at residential centers, where $27.2 \%$ of the alcohol users in Mexico receive care, the psychometric properties of the SADD remain unknown. ${ }^{21}$ Furthermore, there is little evidence of the SADD diagnostic accuracy. Thus, the objective of the present study was to evaluate the psychometric properties and diagnostic accuracy of three SADD versions (15, 14 , and 12 items) in a population receiving care at 30 addiction residential centers.

\section{METHOD}

The current study is part of a research protocol aimed at determining the psychometric properties of a set of 11 self-report clinical scales in a Mexican sample of patients with substance use disorder (SUD) at 30 addiction residential centers localized in Midwestern Mexico (in the states of México, Puebla, Querétaro and Hidalgo, and Mexico City).

\section{Participants}

For this paper, the data of the 570 participants were analyzed (figure 1). The sample comprised 502 (88.1\%) men and $68(11.9 \%)$ women. Participants were aged between 18 and 60 years, were literate and were attending a center for substance use problems, with at least one week of abstinence. Exclusion criteria included: symptoms of psychosis, mania, hypomania or cognitive impairment at the screening.

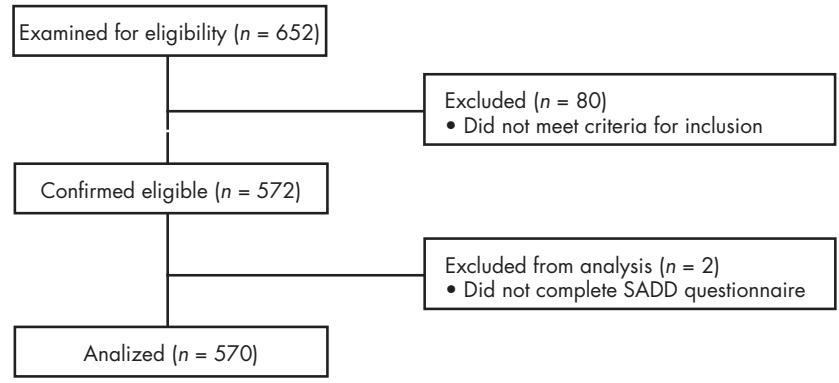

Figure 1. Flow diagram of participants. 


\section{Measures}

Participants completed the Mini International Neuropsychiatric Interview in Spanish (MINI 5.0), ${ }^{22}$ a structured diagnostic interview that explores the major psychiatric disorders in the Diagnostic and Statistical Manual of Mental Disorders (DSM) and the International Classification of Diseases (ICD). ${ }^{23}$ The MINI has shown good validity and reliability, can be administered in a relatively short time period (average $18.7 \pm 11.6 \mathrm{~min}$ ) and there is a Spanish translation of the SADD 15-item version, ${ }^{14}$ which uses a four-point, anchorage, Likert-type scale, with a minimal score of 0 and a maximal score of 45 .

\section{Procedures}

All subjects were recruited for voluntary participation at each center and were assessed for eligibility utilizing the Mini-Mental State Examination (MMSE) in Spanish for dementia $^{24}$ and the MINI 5.0 to assess substance abuse/dependence, as well as other psychiatric conditions. A set of 11 self-report clinical scales was administered to all eligible participants immediately after screening. All interviewers were trained and certified in all study procedures. Each study procedure was approved by the Institutional Review Board of the National Institute of Psychiatry Ramón de la Fuente Muñiz.

\section{Data analysis}

Psychometric analyses included internal consistency using Cronbach's alpha and Pearson correlations. One factor model was tested using maximum likelihood CFA for three SADD versions, considering current tendencies in studies performing CFA. ${ }^{25}$ The goodness-of-fit indixes employed were the following: Chi square $\left(\chi^{2}\right)$; degrees of freedom (df);
Comparative Fit Index (CFI); Root-Mean-Square Error of Approximation (RMSEA); Tucker-Lewis Index (TLI) and Goodness-of-Fit Index (GFI). To calculate diagnostic accuracy for the three SADD versions, we obtained sensitivity, specificity, Positive predictive values (PPV), Negative predictive values (NPV), multilevel likelihood ratios and efficiency values, using diagnoses obtained in the MINI 5.0 as the gold standard. In addition, Receiver Operating Characteristic (ROC) curve analysis was performed to determine the Area under the curve (AUC). Finally, DeLong's test was carried out among SADD versions to determine whether AUC differences were statistically significant. ${ }^{26}$ CFA was conducted using the IBM SPSS AMOS (Analysis of Moment Structures) ver. 22.0 computer package. The remaining analyses were performed using $\mathrm{R}$ ver. 3.0.3 pROC software packages $^{27}$ and epiR. ${ }^{28}$

\section{RESULTS}

The educational level varied significantly between males and females. Most participants reported never having been married and living in urban population (table 1). Finally, 353 males and 47 females had AD, although no statistical difference was found between both groups $\left(\chi_{(1)}^{2}=.041 ; p>.05\right)$.

\section{Reliability and Validity}

The mean for the three SADD scores was 17.3 (standard deviation $[S D]=10.6), 15.8(S D=10.4)$ and $13.8(S D=9)(15$, 14 and 12 items, respectively) in the overall sample. All SADD versions showed good internal consistency $(\alpha=.91$, $\alpha=.92$, and $\alpha=.91$, respectively). The 15 -item questionnaire exhibited significant item-total correlations $>.50$, with the exception of item 9, which had a low correlation (.28). The remaining SADD versions had item-total correlations $>.51$.

Table 1. Demographic characteristics of the sample

\begin{tabular}{|c|c|c|c|c|c|c|c|}
\hline & \multicolumn{2}{|c|}{$\begin{array}{c}\text { Male } \\
(n=502)\end{array}$} & \multicolumn{2}{|c|}{$\begin{array}{c}\text { Female } \\
(n=68)\end{array}$} & \multicolumn{2}{|c|}{$\begin{array}{c}\text { Total } \\
(n=570)\end{array}$} & \multirow[b]{2}{*}{ Statistical differences } \\
\hline & Mean or \% & SD & Mean or $\%$ & SD & Mean or $\%$ & SD & \\
\hline Age & 30.5 & 11 & 29.4 & 10.2 & 30.4 & 10.9 & $t_{(568)}=0.81$ \\
\hline Marital status & & & & & & & $\chi_{(2)}^{2}=4.23$ \\
\hline Married/Cohabitating & 31.3 & & 19.1 & & 29.8 & & \\
\hline Separated/Divorced & 17.3 & & 20.6 & & 17.7 & & \\
\hline Never been married & 51.4 & & 60.3 & & 52.5 & & \\
\hline Education & & & & & & & $\chi_{(3)}^{2}=14.35^{*}$ \\
\hline No education & 2.6 & & 0.0 & & 2.3 & & \\
\hline Elementary/Middle school & 61.6 & & 47.1 & & 59.8 & & \\
\hline High school & 27.8 & & 32.4 & & 28.4 & & \\
\hline College or higher education & 8.0 & & 20.6 & & 9.5 & & \\
\hline Population & & & & & & & $\chi_{(1)}^{2}=1.38$ \\
\hline Rural & 13.0 & & 7.8 & & 12.3 & & \\
\hline Urban & 87.0 & & 92.2 & & 87.7 & & \\
\hline
\end{tabular}


The goodness-of-fit measurements obtained for the 15-item model were as follows: $\chi^{2}=269 ; \mathrm{df}=81 ; \mathrm{CFI}=.95$; RMSEA=.06; $\mathrm{TLI}=.94$, and GFI=.93. With respect to the 14-item model, we observed the following: $\chi^{2}=264 ; \mathrm{df}=70 ; \mathrm{CFI}=.95$; RMSEA=.07; $\mathrm{TLI}=.93$, and GFI=.93. Finally, CFA for the last model (12 observed variables) suggested a model fit similar to the previous ones $\left(\chi^{2}=208 ; \mathrm{df}=50 ; \mathrm{CFI}=.95 ; \mathrm{RMSEA}=.07\right.$, TLI=.93, and $\mathrm{GFI}=.94)$.

\section{Diagnostic Accuracy}

The correlation between SADD and MINI 5.0 scores was $.55(p<.01)$. Receiver Operating Characteristic (ROC) curve analysis revealed that the 15- and 14-item questionnaires accounted for $85 \%$ of the AUC (95\% confidence interval [95\% $\mathrm{CI}, .81, .89])$, whereas the 12-item questionnaire accounted for $84 \%$ of the AUC $(95 \% \mathrm{CI}, .80, .88)$ (figure 2$)$.

There were three cut-off points for the SADD: a cutoff point of 14 optimized sensitivity (.80) though specificity (.81); a cut-off point of 12 optimized sensitivity (.80) though specificity (.81) and a cut-off point of 10 sensitivity $(.81)$ specificity $(.80)$, respectively, in the study sample. DeLong's test indicated that there were no statistically significant differences among the AUC of the 15- and 14-item SADD versions $(Z=-.0668 ; p=.9467), 15$ - and 12-item versions $(Z=1.1671 ; p=.2432)$, and the 14 - and 12-item versions $(Z=1.4007 ; p=.1613)$ (table 2$)$.

\section{DISCUSSION AND CONCLUSION}

This study sought to evaluate three versions of the Short Alcohol Dependence Data Questionnaire (15-, 14- and 12-item models) through Confirmatory Factorial Analysis (CFA) and Receiver Operating Characteristic (ROC) curves. The three SADD versions showed good internal consistency (between .91 and .92), evidence for construct validity and a fair discriminatory diagnostic capacity. These findings prove that SADD is a single-dimension scale and supports the identification of patients with AD.

According to previous studies, item 9 (Do you try to control your drinking by giving it up completely for days or weeks at a time?) showed low item-score and within items correlations, ${ }^{15}$ which suggest that limit setting is not a common trait in people with AD. Likewise, items 13 (The morning after a heavy drinking session, do you go out of your way to avoid people?) and 15 (Do you go drinking and the next day find you have forgotten what happened the night before?) are directly associated with alcohol use-related problems rather than the ADS. ${ }^{17,29,30}$ However, there is little evidence on these measurement problems in the literature. Through the analysis of three SADD versions, we observed that the properties of the 12-item version barely differ from the 15- and 14-item versions, suggesting that items 9, 14 and 15 may not add significant information about the behavior of patients with alcohol use.

A CFA with a SADD one-factor solution resulted in a fair model fit for the three versions. This finding supports the Davidson et al. ${ }^{15}$ hypothesis that assumes the SADD single-factor structure. In addition, it adds to evidence pointing out the homogeneity of the ADS. ${ }^{31-34}$

On the other hand, given that the dissemination of screening procedures is conducted in Mexican primary care addiction centers, the testing accuracy of screening becomes a main concern. Therefore, the determination of an optimal cut-off score for a specific population improves the practices, allowing clinicians to rule in or rule out patients into treatment with accuracy. ${ }^{35}$ The diagnostic properties of the cut-off scores determined by operating characteristics curves of SADD imply that, independently of the version used, questionnaire accuracy can be trusted. However, the selection is recommended of a specific cut-off score according to the objective of the screening (whether or not higher specificity or higher sensitivity is required).
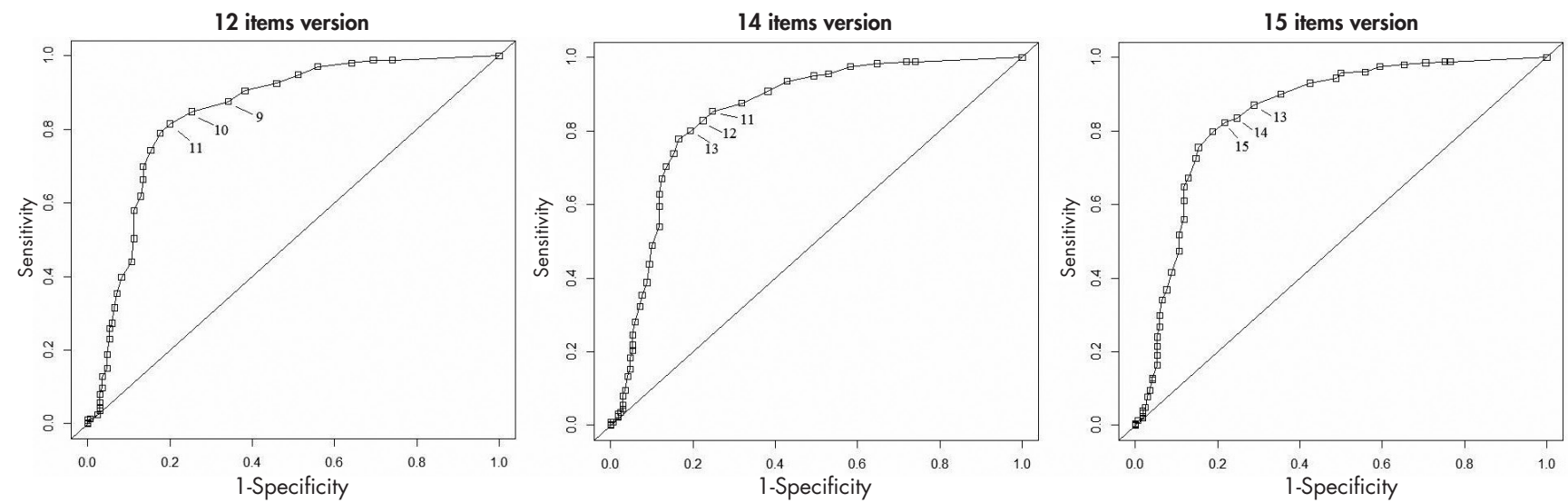

Figure 2. Receiver Operating Characteristic (ROC) curves from Short Alcohol Dependence Data Questionnaire (SADD) versions for Alcohol dependence (AD) screening. 
Psychometric Properties and Diagnostic Accuracy of SADD

Table 2. Measures of diagnostic accuracy for the three Short Alcohol Dependence Data Questionnaire (SADD) models at several of cut-off scores

\begin{tabular}{|c|c|c|c|c|c|c|}
\hline $\begin{array}{l}\text { Cut-off score } \\
\text { (Endorsed Alcohol } \\
\text { Dependence) }\end{array}$ & $\begin{array}{l}\text { Sensitivity } \\
(95 \% \mathrm{CI})\end{array}$ & $\begin{array}{l}\text { Specificity } \\
(95 \% \text { CI) }\end{array}$ & $\begin{array}{l}\text { Likelihood ratio } \\
\text { (95\% CI) }\end{array}$ & $\begin{array}{c}\text { Positive } \\
\text { Predictive value } \\
\text { (Cl 95\%) } \\
\end{array}$ & $\begin{array}{c}\text { Negative } \\
\text { Predictive value } \\
\text { (Cl 95\%) } \\
\end{array}$ & $\begin{array}{l}\text { Diagnostic } \\
\text { efficiency } \\
(95 \% \mathrm{Cl}) \\
\end{array}$ \\
\hline \multicolumn{7}{|l|}{15 items } \\
\hline $11(n=397)$ & $.87(.83, .90)$ & $.71(.64, .78)$ & $3.02(2.38,3.83)$ & $.88(.84, .91)$ & $.70(.63, .77)$ & $.82(.78, .85)$ \\
\hline $12(n=376)$ & $.83(.79, .87)$ & $.75(.68, .82)$ & $3.38(2.59,4.41)$ & $.89(.85, .92)$ & $.66(.59, .73)$ & $.81(.77, .84)$ \\
\hline $13(n=366)$ & $.82(.78, .86)$ & $.78(.71, .84)$ & $3.78(2.83,5.04)$ & $.90(.86, .93)$ & $.65(.58, .72)$ & $.81(.77, .84)$ \\
\hline $14(n=351)$ & $.80(.75, .84)$ & $.81(.74, .87)$ & $4.24(3.09,5.81)$ & $.91(.87, .94)$ & $.63(.56, .69)$ & $.80(.76, .83)$ \\
\hline $15(n=328)$ & $.76(.71, .80)$ & $.85(.78, .90)$ & $4.94(3.45,7.06)$ & $.92(.89, .95)$ & $.60(.53, .66)$ & $.78(.74, .81)$ \\
\hline \multicolumn{7}{|l|}{14 items } \\
\hline $9(n=404)$ & $.88(.84, .91)$ & $.68(.61, .75)$ & $2.75(2.20,3.44)$ & $.87(.83, .90)$ & $.70(.62, .77)$ & $.81(.78, .84)$ \\
\hline $10(n=383)$ & $.85(.81, .89)$ & $.75(.68, .82)$ & $3.45(2.65,4.50)$ & $.89(.85, .92)$ & $.68(.61, .75)$ & $.82(.78, .85)$ \\
\hline $11(n=369)$ & $.83(.79, .86)$ & $.78(.71, .84)$ & $3.70(2.79,4.92)$ & $.90(.86, .93)$ & $.66(.59, .72)$ & $.81(.77, .84)$ \\
\hline $12(n=353)$ & $.80(.76, .84)$ & $.81(.74, .86)$ & $4.12(3.02,5.62)$ & $.91(.87, .93)$ & $.63(.56, .70)$ & $.80(.76, .83)$ \\
\hline $13(n=339)$ & $.78(.73, .82)$ & $.84(.77, .89)$ & $4.72(3.35,6.65)$ & $.92(.88, .94)$ & $.61(.55, .68)$ & $.79(.75, .82)$ \\
\hline \multicolumn{7}{|l|}{12 items } \\
\hline $7(n=427)$ & $.90(.87, .93)$ & $.62(.54, .69)$ & $2.37(1.95,2.87)$ & $.85(.81, .88)$ & $.73(.65, .80)$ & $.81(.78, .85)$ \\
\hline $8(n=408)$ & $.88(.84, .91)$ & $.66(.58, .73)$ & $2.56(2.07,3.17)$ & $.86(.82, .89)$ & $.69(.61, .76)$ & $.81(.77, .84)$ \\
\hline $9(n=382)$ & $.85(.81, .88)$ & $.75(.67, .81)$ & $3.35(2.58,4.35)$ & $.89(.85, .92)$ & $.68(.60, .74)$ & $.81(.78, .84)$ \\
\hline $10(n=360)$ & $.81(.77, .85)$ & $.80(.73, .86)$ & $4.08(3.01,5.52)$ & $.91(.87, .93)$ & $.65(.58, .71)$ & $.81(.77, .84)$ \\
\hline $11(n=346)$ & $.79(.75, .83)$ & $.82(.76, .88)$ & $4.48(3.22,6.22)$ & $.91(.88, .94)$ & $.62(.56, .69)$ & $.80(.76, .83)$ \\
\hline
\end{tabular}

In Mexico, another measure used to evaluate alcohol use is the Alcohol Use Disorders Identification Test (AUDIT). However, since this is a test designed specifically to increase the detection of a spectrum of alcohol problems, it exhibits a greater capacity to screen less severe alcohol problems, such as at-risk, harmful and hazardous drinking, and low sensitivity to dependence. ${ }^{36-38}$ Thus, SADD raises the alternative of identifying persons with AD in primary-care settings.

A limitation of this study was the small size of women sample for conducting subgroup analyses and for identifying gender-specific, optimal cut-off scores. A second limitation was the amount of self-report scales administered, which could result in biased answers as a result of respondent fatigue.

In conclusion, the three SADD versions are reliable and valid measures to assess AD. Moreover, they show optimal cut-off scores for the improvement of patient identification treatment centers and, consequently, referral to specialized care. Future studies should examine the operating characteristics of the SADD in different clinical samples (e.g., outpatients, women, psychiatric samples) to determine specific optimal cut-off points and to test the generalizability of these findings.

\section{Funding}

This study is part of the project "Development of a Clinical Trial Network on Addiction and Mental Health in Mexico" funded by a grant from the U.S. Department of State (Grant No. SINLEC11GR0015 / A001 / A002) awarded to the National Institute of Psychiatry Ramón de la Fuente Muñiz in Mexico. The U.S. Department of State had no role in the study design, data collection, analysis or interpretation of the data, writing the manuscript or the decision to submit this paper for publication.

\section{Conflict of interest}

No author of this paper has a conflict to interest, including specific financial interest, relationships, and/or affiliations revelant to the subject matter included in this manuscript.

\section{Acknowledgements}

The authors would like to thank the institutional support received by: Instituto para la Atención y Prevención de las Adicciones en la Ciudad de México, Instituto Mexiquense Contra las Adicciones, Consejo Estatal Contra las Adicciones de Hidalgo, Consejo Estatal Contra las Adicciones de Puebla, Consejo Estatal Contra las Adicciones de Querétaro, and the Florida Node Alliance at the University of Miami. We also wish to thank David Sheehan M.D. for allowing the use of the Spanish-language adaptation of the 5th version of the Mini International Neuropsychiatric Interview in Spanish.

\section{REFERENCES}

1. Nutt D, King LA, Phillips LD. Drugs Harms in the UK: a Multicriteria Decision Analysis. Lancet 2009;376:1558-1565.

2. Mongan D, Hope A. Nelson M. Social consequences of harmful use of alcohol in Ireland. Dublin: Health Research Board;2009.

3. World Health Organization. Global Health Risks. Mortality and Burden of Disease Attributable to Selected Major Risks. Geneva: World Health Organization;2004.

4. Lozano R, Gómez-Dantes H, Garrido-Latorre F, Jiménez-Corona A, et al. La carga de enfermedad, lesiones, factores de riesgo y desafíos para el sistema de salud en México. Salud Publica Mex. 2013;55(6):580-594.

5. World Health Organization. Composite International Diagnostic Interview (CIDI), core version 1.0. Geneva: World Health Organization;1989.

6. Sheehan D, Lecrubier Y, Sheehan K, Amorim P, et al. The Mini International Neuropsychiatric Interview (MINI): The Development and Validation of a Structured Diagnostic Psychiatric Interview for DSMIV and ICD-10. J Clin Psychiat.1998;59(20):22-23. 
7. Cherpitel CJ. Brief Screening Instruments for Alcoholism. Alcohol Health Res World 1997;21(4):348-351.

8. Dawe S, Loxton NJ, Hides L, Kavanagh DJ, et al. Review of Diagnostic Screening Instruments for Alcohol and Other Drug Use and Other Psychiatric Disorders. Australian Government Department of Health: Australia;2002.

9. Edwards G, Gross MM. Alcohol dependence: provisional description of a clinical syndrome. Br Med J.1976;1:1058-1061.

10. Stockwell T, Hodgson R, Edwards G, Taylor C, et al. The Development of a Questionnaire to Measure Severity of Alcohol Dependence. Br J Addiction.1979;74:79-87.

11. Davidson R, Raistrick D. The validity of the Short Alcohol Dependence Data (SADD) Questionnaire: A short self-report questionnaire for the assessment of alcohol dependence. Br J Addiction 1986;81:217-222.

12. Skinner HA, Horn JL. Alcohol Dependence Scale (ADS): Users Guide. Toronto: Addiction Research Foundation;1984.

13. Saxon AJ, Kivlahan DR, Doyle S, Donovan DM. Further validation of the Alcohol Dependence Scale as an index of severity. J Stud Alcohol Drugs 2007;68(1):149-156.

14. Raistrick DS, Dunbar G, Davidson RJ. Development of a questionnaire to measure alcohol dependence. Br J Addiction 1983;78:89-95.

15. Davidson R, Bunting B, Raistrick D. The homogeneity of the alcohol dependence syndrome: A factor analysis of the SADD questionnaire. Br J Addiction 1989;84:907-915.

16. Jorge MR, Masur J. The use of the Short-Form Alcohol Dependence Data Questionnaire (SADD) in Brazilian Alcoholic Patients. Br J Addiction 1985;80:301-305.

17. Abraham J, Chandrasekaran R. The Severity of Alcohol Dependence Data Questionnaire: Modification and Validation. Indian J Psychiatr.1997;39(1):8-12.

18. Echeverria L, Oviedo P, Ayala H. Breve Escala sobre Dependencia al Alcohol (BEDA). En: Ayala H, editor. Manual de Auto Ayuda para Personas con Problemas en su Forma de Beber. México: Porrúa;1998.pp105-112.

19. Sánchez J. Adaptación de un instrumento de tamizaje para la población mexicana que consume alcohol. (Ba thesis). México: Universidad Nacional Autónoma de México;2005.

20. Echeverría L, Ruíz GM, Salazar ML, Tiburcio MA, et al. Manual de Detección Temprana e Intervención Breve para Bebedores Problema. México: Universidad Nacional Autónoma de México, Facultad de Psicología;2005.

21. Secretaría de Salud, Centro Nacional para la Prevención de las Adicciones, Comisión Nacional contra las Adicciones, Instituto Nacional de Salud Pública, Instituto Nacional de Psiquiatría. National Survey of Addictions 2011. México: Secretaría de Salud. Centro Nacional para la Prevención de las Adicciones. Comisión Nacional contra las Adicciones. Instituto Nacional de Salud Pública. Instituto Nacional de Psiquiatría;2012.

22. Sheehan DV, Lecrubier Y, Harnett-Sheehan K, Amorim P, Janavs J, Weiller E, Hergueta T, Baker R, Dunbar G: The M.I.N.I. International Neuropsychiatric Interview (M.I.N.I.): The Development and Validation of a Structured Diagnostic Psychiatric Interview. J. Clin Psychiatry, 1998;59(suppl 20):22-33.
23. Sheehan DV, Lecrubier Y, Harnett-Sheehan K, Janavs J, et al. Reliability and Validity of the M.I.N.I. International Neuropsychiatric Interview (M.I.N.I.): According to the SCID-P. European Psychiatry 1997;12:232-241.

24. Reyes S, Beaman PE, García-Peña C, Villa MA, et al. Validation of a modified versión of the Mini-Mental State Examination (MMSE) in Spanish. Aging Neuropsychol C.2004;11:1-11.

25. Jackson DL, Gillaspy JA, Purc-Stephenson R. Reporting practices in confirmatory factor analysis: an overview and some recommendations. Psychol Methods 2009;14(1):6-23.

26. DeLong ER, DeLong DM, Clarke-Pearson DL. Comparing the areas under two or more correlated receiver operating characteristic curves: a nonparametric approach. Biometrics 1988;44:837-845.

27. Robin X, Turck N, Hainard A, Tiberti N, et al. pROC: an open-source package for $\mathrm{R}$ and $\mathrm{S}+$ to analyze and compare ROC curves. BMC Bioinformatics 2011;12(1):77.

28. Stevenson M, Nunes T, Sanchez J, Thornton R, Reiczigel J, et al. epiR: An $R$ package for the analysis of epidemiological data. The Comprehensive R Archive Network website. URL http://CRAN.R-project.org/ package $=$ epiR. Accessed 2014 September 22. $R$ package version 0.9-59.

29. Edwards G. The Alcohol Dependence Syndrome: a Concept as Stimulus to Inquiry. British Journal of Addiction 1986;81:171-183.

30. Li TK, Hewitt BG, Grant BF. The Alcohol Dependence Syndrome, 30 years later: a commentary. Addiction 2007;102:1522-1530.

31. Bucholz KK, Hesselbrock VM, Shayka JJ, Nurnberger Jr. JI, et al. Reliability of individual diagnostic criterion items for psychoactive substance dependence and the impact on diagnosis. J Stud Alcohol 1995;56(5):500-505.

32. Feingold A, Rounsaville B. Construct validity of the dependence syndrome as measure by DSM-IV for different psychoactive substances. Addiction 1995;90(12):1661-1669.

33. Langenbucher J, Martin CS, Labouvie E, Sanjuan PM, et. al. Toward the DSM-V: the Withdrawal-Gate Model versus the DSM-IV in the diagnosis of alcohol abuse and dependence. J Consult Clin Psych. 2000;68(5):799-809.

34. Mohan D., Hem Sethi RR. Unidimensionality of Alcohol Dependence Syndrome. Drug Alcohol Depen.1995;37:163-166.

35. Gore KL, McCutchan PK, Prins A, Freed MC, et al. Operating characteristics of the PTSD checklist in a military primary care setting. Psychol Assesment 2013;25(3):1032-1036.

36. Barry KL, Fleming MF. The Alcohol Use Disorders Identification Test (AUDIT) and the SMAST-13: predictive validity in a rural primary care sample. Alcohol Alcoholism.1993;28(1):33-42.

37. Morton JL, Jones TV, Manganaro MA. Performance of alcoholism screening questionnaires in elderly veterans. Am J Med. 1996;101(2):153-159.

38. Schmidt A, Barry KL, Fleming MF. Detection of problem drinkers: the Alcohol Use Disorders Identification Test (AUDIT). South Med J. 1995;88(1):52-59. 